\title{
Erratum to: Synthesis of Nickel-Containing Sapropel Based Catalysts and Their Study in the Liquid-Phase Hydrogenation of Nitrobenzene
}

\author{
E. N. Terekhova ${ }^{a, *}$ and O. B. Belskaya ${ }^{a}$ \\ ${ }^{a}$ Center for New Chemical Technologies, Institute of Catalysis, Siberian Branch, \\ Russian Academy of Sciences, Omsk, 644040 Russia \\ *e-mail: e.terechova@ihcp.ru
}

Received October 4, 2021; revised October 4, 2021; accepted October 4, 2021

DOI: $10.1134 / \mathrm{S} 1070427221080206$

In the text body the designations CM-Mk and CM-Mak should be replaced by CM-Mac. In the text body the designations CM-Ok and CM-Oak should be replaced by CM-Oac. In the Fig. $3 \mathrm{NiUMk}$, $\mathrm{Ni}-\mathrm{Cu} / \mathrm{CMak}$, and $\mathrm{Ni}-\mathrm{Mo} / \mathrm{CMak}$ should be replaced by $\mathrm{NiCMac}, \mathrm{Ni}-\mathrm{Cu} / \mathrm{CMac}$, and $\mathrm{Ni}-\mathrm{Mo} / \mathrm{CMac}$, respectively.

The original article can be found online at https://doi.org/10.1134/S1070427221020129 